\title{
Experiment on the Electroforming NiCo-SiC Alloy
}

\author{
Xiaohu ZHENG ${ }^{1, a, ~}{ }^{*}$, Xiaohong $\mathrm{ZHU}^{2, b}$ \\ ${ }^{1}$ Faculty of Mechanical Engineering, Huaiyin Institute of Technology, Huaian, Province 223003, \\ China \\ ${ }^{2}$ Sizheng Department, Jiangsu Food \& Pharmaceutical Science College, Huaian, Province 223003, \\ China
}

email: hyzxh@126.com, "corresponding author

Keywords: Electrodeposition, Nanocomposites, Electromagnetic Property, Micro sensor

\begin{abstract}
Electrolytic codeposition technique was adopted in the deposition of NiCo-SiC coating on the stainless substrate, using nickel alloyed with iron as the binder phase with SiC as dispersed particles. The results indicated that the deposit with $\mathrm{SiC}$ nanoparticles was level and compact; the crystal-planes of the deposit were (111), (220) and (200). The resistivity of deposit was about $30 \mu \Omega \cdot \mathrm{cm}$. when the $\mathrm{Fe}($ wt.\%) ranged from $10 \%$ to $50 \%$ in the deposit, the electrodeposit $\mathrm{Ni}-20 \% \mathrm{Fe}-\mathrm{SiC}$ has a strong paramagnetism effect with the smallest coercivity of $2.75 \times 10-2 \mathrm{~A} / \mathrm{m}$. The remanence showed a monotonic decrease with the increasing iron content in deposit. Which proved that the electroformed $\mathrm{NiCo}-\mathrm{SiC}$ alloy has good electromagnetic property and higher corrosion resistance than those of electroforming Ni-Co alloy. It is a promising material in the fabrication of micro actuator.
\end{abstract}

\section{Introduction}

NiCo deposit has a compact structure, bright and smooth surface and was widely used in the production of new materials that required specific mechanical, chemical and/or physical properties $[1,2,3]$. These alloys also exhibit excellent properties of levelling, high hardness, thermally stable, and fine magnetic properties. Various compositions of Ni-Co alloys such as Permalloy (Ni-20\%), Invar alloy (Ni-64\%Fe) and high strength $\mathrm{Ni}-\mathrm{Fe}$ alloy can be used to produce micro sensor, micro actuators and other MEMS device [4,5]. David Flynn compared various microscale magnetic components and described a novel method to manufacture and assemble a Ni-20\%Fe microconductor that is based on flip chip bonding[6]. The micro component fabricated with electroforming Ni-Co alloy could be integrated with other materials easily [7]. But the corrosion resistance of Ni-Co deposit was lower than that of the electroforming $\mathrm{Ni}$. SiC nano particles has been studied as a promising material in corrosion protection. Gajendra Sharma concluded that the $\mathrm{Ni}-\mathrm{Co}-\mathrm{SiC}$ composite coating shows substantial improvement in the hardness as compared to pure $\mathrm{Ni}$ plating [8]. Electroforming $\mathrm{Ni}$ alloys with nano $\mathrm{SiC}$ has a smaller grain size and finer property than that of the electroforming $\mathrm{Ni}$, moreover, nano $\mathrm{SiC}$ could improve the corrosion resistance of the deposit considerably [9]. Min-Chieh Choua revealed that adding SiC to the Ni-P alloy matrix substantially reduces the residual stress in the deposit and, therefore, eliminates surface cracking.

In the present work, the nickel-iron deposit with nanocomposites $\mathrm{SiC}$ and its electromagnetic property were investigated. The work will be benefit to the fabrication of many magnetic microactuators with Ni-Co-SiC electrodeposits.

\section{Experimental Procedure}

There are many kinds of solution for Ni-Co deposit. An acid sulphate solution, containing metal sulphates and some brightener, was chosen for this study [4]. The main content of solution and devices using in the experiment was presented as follows:

Main Salts: Nickel Sulphate, Ferrous Sulfate. Buffer Solution and Stabilizer: Boric acid, Citric acid. Anode activators and conductive agent: Sodium Chloride, Sodium Sulphate and some additive, $50 \mathrm{~nm}$ grain size SiC nanoparticles: $2-3 \mathrm{~g} / \mathrm{L}$. When preparing metal salt solutions of different 
concentrations, the amount of Nickel Sulphate was $250 \mathrm{~g} / \mathrm{l}$, the amount of Co ion was adjusted by the Sulfate additives. The main electroforming parameters: $\mathrm{PH}$ value of the solution was less than 2.5, current density was set from 2.5 to $4 \mathrm{~A} / \mathrm{dm}^{2}$, stiring velocity: $500-700 \mathrm{rpm} / \mathrm{min}$, the solution temperature was ranged from 50 to $60^{\circ} \mathrm{C}, \mathrm{CoSO}_{4} \cdot 7 \mathrm{H}_{2} \mathrm{O}: 3-7 \mathrm{~g} / \mathrm{l}$, several different process parameters were adopted in the experiment. The composition and range of experimental operating parameters were given in table 1.

\begin{tabular}{cc} 
Table 1 Operational parameters of Ni-Fe-SiC composite coating \\
\hline $\mathrm{NiSO}_{4} \cdot 6 \mathrm{H}_{2} \mathrm{O}$ & $250 \mathrm{~g} / \mathrm{l}$ \\
$\mathrm{NiCl}_{2} \cdot 6 \mathrm{H}_{2} \mathrm{O}$ & $30 \mathrm{~g} / \mathrm{l}$ \\
$\mathrm{H}_{3} \mathrm{BO}_{3}$ & $40 \mathrm{~g} / \mathrm{l}$ \\
$\mathrm{CoSO}_{4} \cdot 7 \mathrm{H}_{2} \mathrm{O}$ & $3-7 \mathrm{~g} / \mathrm{l}$ \\
$\mathrm{NaSO}_{4} \cdot 10 \mathrm{H}_{2} \mathrm{O}$ & $10 \mathrm{~g} / \mathrm{l}$ \\
$\mathrm{SiC} \mathrm{particles}$ & $2-3 \mathrm{~g} / \mathrm{l}$ \\
Parameter for equipment setup & $55^{\circ} \mathrm{C}$ \\
Temperature of bath & $<2.5$ \\
PH & $2.5-4 \mathrm{~A} / \mathrm{dm}^{2}$ \\
Current density & $100-300 \mathrm{~min}$ \\
Plating time & $600 \mathrm{rpm}$ \\
Stirring rate &
\end{tabular}

\section{Results and Discussion}

The properties of Ni-Co deposit are affected by several factors such as the texture, compositions, etc. The main properties of the plating were presented as follows:.

Surface Morphology of the Plating. The deposit surface morphology was sensitive to the impurity in the solution. Some organic additives were adopted in the experiment to obtain the bright and smooth plating surface. Ni-Co-SiC deposit has a more compact structure than that of pure Ni. Fig. 1 was the surface morphology SEM photograph of the electrodeposit $\mathrm{Ni}$ and $\mathrm{Ni}-22.27 \% \mathrm{Co}-\mathrm{SiC}$. The corrosion test of the deposit was performed subsequently. The corrosion rate of Ni-22.27\% Co -SiC deposit was $0.17 \mathrm{mg} / \mathrm{dm}^{2}$ per hour in $2 \mathrm{M}$ HCL solution, which was smaller than that of the electroforming Ni-20\% Co $\left(0.23 \mathrm{mg} / \mathrm{dm}^{2}\right.$ per hour $)$. The results indicated that the corrosion rate of the deposit be improved significantly with the ad SiC particles. The deposition rate is about $5 \mu \mathrm{m}-8 \mu \mathrm{m}$ per hour. The electrodeposits showed no curling or buckling after removing from the substrate. Which indicated that internal stresses was relatively low.

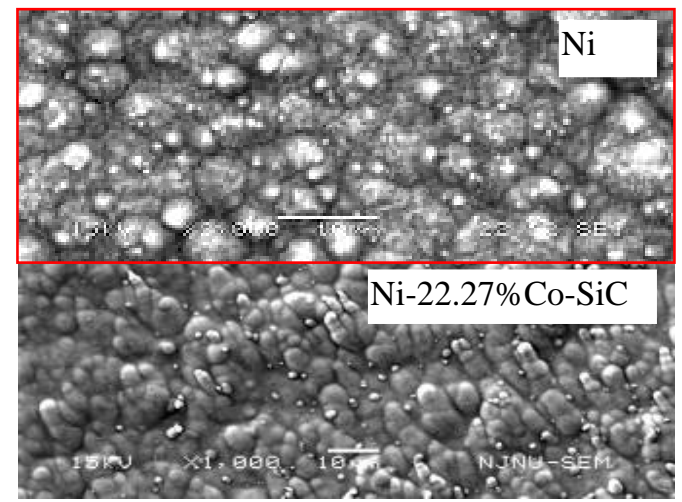

Fig.1. SEM photograph of deposit (Ni, Ni-22.27\% Co -SiC)

Fig. 2 showed the X-ray diffraction of electroforming Ni-Co-SiC alloy. The plating has a well crystal structure. The X-ray diffraction peak were (111),(220) and (200). When the Co content reached to $41 \%$, the highest diffraction peak fall from (111) to (220). Pure Ni has a diffraction peak of (111).The change of the crystalline orientation may be attributed to the cathodic over-voltage and the change of the ion concentration. There are some inhibition material such as $\mathrm{H}_{2}, \mathrm{Ni}(\mathrm{OH})_{2}$ on the cathode-solution interface. They not only affected the plating morphology and the selective adsorption, but also altered the crystal growth mode. 


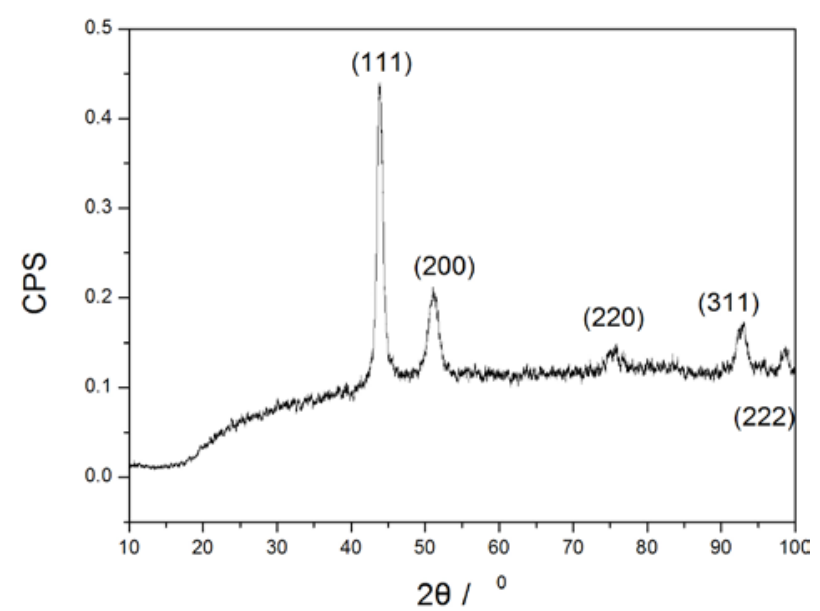

Fig.2. X-ray diffraction of the deposit

Electromagnetic Property. To compare the magnetism property with permalloy, the hysteresis loop of $\mathrm{Ni}-30 \% \mathrm{Co}-\mathrm{SiC}$ deposit and permalloy (IJ85) were tested under the same condition. As showed in Fig.3, Ni-30\% Co -SiC deposit has superparamagnetic characters with magnetic remnant was $0.528 \mathrm{~mA} \cdot \mathrm{m}^{2}$, coercivity was $2.88 \times 10^{-2} \mathrm{~A} / \mathrm{m}$. Moreover $\mathrm{Ni}-20 \%$ Co $-\mathrm{SiC}$ has a smallest coercivity value of $2.75 \times 10^{-2} \mathrm{~A} / \mathrm{m}$, which was less than that of IJ85 permalloy. Saturated Magnetization value of deposit was only $10 \%$ of the IJ85 alloy. The remanence and coercivity comparison of the deposit was showed in Fig. 4. Ni-20\%Co-SiC deposit has a lowest remanence, and the coercivity show a monotonic decrease with increasing the iron content in deposit. The test data indicate that the deposit has a satisfactory magnetism property. The resistivity of deposit was about $30 \mu \Omega \cdot \mathrm{cm}$, when the iron content ranged from $10 \%$ to $50 \%$ in the deposit.

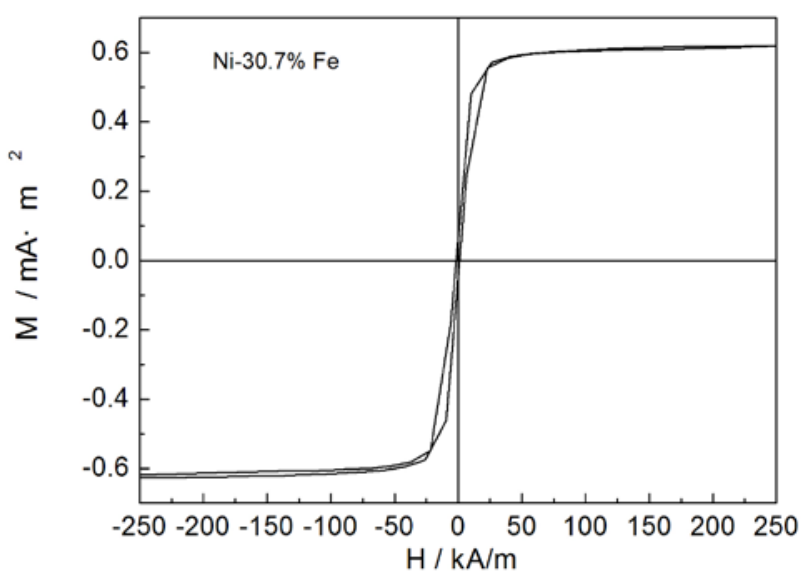

Fig.3. The hysteresis loop of electroforming alloy

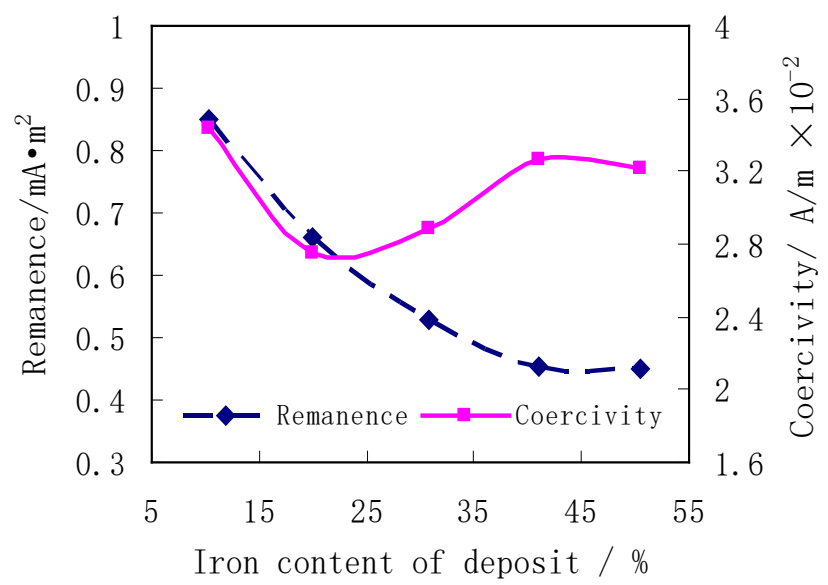

Fig.4. The Co content of /deposits against the coercivity and remanence 


\section{Conclusions}

$\mathrm{Ni}$-Co-SiC electrodeposit technology and physical property was discussed in this paper, The hysteresis loop of electroforming alloy and the trend of the iron content in the deposit against the coercivity, remanence were given. From the experiment it can concluded that the Ni-Co-SiC electrodeposit has fine electromagnetic property, high corrosion resistance, compact structure, and could be used in MEMS actuator manufacture.

\section{References}

[1] Czerwinski F, Grain Size-Internal Stress Relationship in Iron-Nickel Alloy Electrodeposits . J. Electrochem. Soc. 1996; 143:3327-3332.

[2] K.Msellak, J.P.Chopart, O. Magnetic field effects on Ni-Fe alloys codeposition. Journal of Magnetism and Magnetic Materials 2004;281:295-304.

[3] Guo Zhan-cheng. Magnetic properties and microstructure of electrodeposited Fe and Ni alloy foil. The Chinese Journal of Nonferrous Metals 2004; 14:273-279.

[4] Martincic E, Dufour-Gergan E, Bosseboeuf A, et al, Activities of the PFM on permalloy thin films deposition and magnety devices. Preparation ,Properties and Application of Thin Ferromagnetic Films 2000;16:93-100.

[5] Y. Zhuang, M. Vroubel, B. Rejaei. Integrated RF inductors with micro-patterned NiFe core. Solid-State Electronics 2007; 51:405-413.

[6] DAVID FLYNN. A Comparison of Various magnetic thin films for the application of microscale magnetic components. Journal of Physics: Conference Series 2006;34:112-117.

[7] Yalcinkaya Arda D.; Urey Hakan; Holmstrom Sven. NiFe Plated Biaxial MEMS Scanner for 2-D Imaging. IEEE Photonics Technology Letters 2007; 19:330-332.

[8] GAJENDRA SHARMA,R K YADAVA,V K SHARMA. Characteristics of electro codeposited Ni-Co-SiC composite coating. Bull Mater. Sci. 2006;29 (5): 491-496.

[9] Low C. T.J., Wills R.G.A., Walsh F.C.. Electrodeposition of composite coatings containing nanoparticles in a metal deposit. Surface and Coatings Technology 2006; 201:417-426. 